\title{
Product/Business Portfolio management: Logic, structural, and managerial implications
}

\author{
S. Shabalala
}

Department of Business Studies, University of Zimbabwe, Harare, Zimbabwe

The objective and scope of this article are to discuss the logic of Product/Business Portfolio management and to demonstrate how the expected optimal results of such management are undermined, if not completely undermined by factors which are quintessential to organization circumstances. These factors include, among other things, organizational structural attributes (differentiation, integration systems, power distribution, units inter. dependences etc.), information availability, personal values of managers, reward systems, etc. In discussing the issues mentioned above the sequence will be as follows: The overalt look at the basic concept of Product/Business Portfolio strategic management; the general limitations of the normative-rational assumptions of Strategic Business Units (SBUs) Portfolio management; the specific attention to be paid to individual organizational and managerial factors as they affect strategic management in diversified companies; and the implications of the above issues to top management of business institutions.

S. Afr. J. Bus. Mgmt. 1985, 16: $18-26$

Die doel en omvang van hierdie artikel is 'n bespreking van Produk-/Besigheidsportfoliobestuur en om aan te toon hoe verwagte optimale resultate ondermyn word deur faktore wat vir organisasie-omstandighede van kernbelang is. Hierdie faktore sluit onder andere organisasiestruktuur. eienskappe (differensiasie, geïntegreerde sisteme, magsverspreiding, interafhanklikheid van eenhede, ens.), beskikbaarheid van intigting, persoonlike waardes van bestuurders, vergoedingstelsels, ens., in. Die bespreking van hierdie elemente word opvolgend aangebied: Eerstens 'n oorhoofse benadering tot die basiese konsepte van die strategiese bestuur van produk-/besigheidsportfolios; die algemene beperking op die normatiewe-rasionele voorveronderstellings in verband met strategiese besigheidseenhede-portfoliobestuur, volg daarna. Laastens word spesifieke aandag gewy aan individuele organisasie- en bestuursfaktore soos dit strategiese bestuur in gediversifiseerde maatskappye beinvloed en die implikasies hiervan vir topbestuur. S.Afr. Tydskr. Bedryfsl. 1985, 16: 18-26

\section{The basic concept of Product/Business Pontfolio management}

The necessity to conduct product or business portfolio analysis in strategic corporate planning, has been motivated by the realization of multi-divisional corporations that it is more important to optimize the overall corporate earnings than just earnings of divisions or businesses operating as individual elements of the corporate 'octopus'.

Multi-divisional or multi-products corporations have grown in size mainly via either internal growth or growth through mergers and acquisitions. To manage multi-divisional, multibusiness, or multi-products corporations decentralized organization structures and decision-making are required. Principally, financially strong corporations, usually because of their market shares, experience, and scale effects, have considered it prudent to diversify their business operations from their earliest bases to withstand threats, and to seize opportunities provided by competition, technological changes, changes in demand, market characteristics, etc. Basically there are two types or kinds of corporate diversification, namely concentric and conglomerate. The former is also described as related diversification because the nature of various lines of businesses are closely related and usually keyed to common technology, customer usage, distribution, methods of operation, managerial know-how, etc. On the other hand, conglomerate diversification is 'unrelated or pure diversification', whereby the business elements have no true strategic fit among themselves (Thompson \& Strickland, 1980). In Zimbabwe, corporations like Anglo-American, Delta Corporation, Lonrho, and TA Holdings Ltd have followed conglomerate diversification. Phillips Electrical Company and Hunyani Holdings have basically followed concentric diversification.

The business acquired when corporations follow conglomerate diversification strategies are usually expected to meet certain minimum standards of profitability, growth rate, managerial expertise, etc.

The factors that usually motivate corporations to pursue diversification strategies are numerous, but the following are important:

(i) A desire to strike a match between a cash-rich, opportunity-poor company and an opportunity-rich, cash-poor firm.

(ii) To enter product/market areas with counter seasonal or counter cyclical sales pattern so as to smoothen sales patterns and profits.

(iii) To merge an opportunity-poor, skill-rich company with an opportunity-rich, skill-poor company.

(iv) To strike a marriage between a highly leveraged firm and

\section{S. Shabalala}

Department of Business Studies, University of Zimbabwe, Box MP 167, Mt. Pleasant, Harare, Zimbabwe 
a debt-free firm so as to balance the capital structure of the former and increase its borrowing capacity.

(v) To meet the power aggrandizment needs of some members of top management.

(vi) To exploit market opportunities, using the company's distinctive competence in such areas as technology, marketing, raw materials, human resources skills, etc. (Thompson and Strickland, 1980).

Although it is not the purpose of this article to discuss the pros and cons of conglomerate and concentric diversification strategies, it can be stated, in passing, that if a corporation wants to grow from what it can do better and to maintain its distinctive competence, a concentric diversification strategy has more to offer than a conglomerate one. This should not be taken to mean that there can be no benefits accruing to a corporation pursuing a conglomerate diversification strategy, such as improved sales, profits, and growth owing to entering businesses with better economic potential than the existing corporate base business(es). The stabilization of sales, profits etc. is also a goal worth pursuing.

\section{The SBU stratetic planning logic}

The portfolio planning approach represents an attempt to achieve integrated planning where the corporation is composed of sub-units, sometimes referred to as strategic business units (SBUs). The underlying objective is to prevent sub-units from optimizing their individual interests which may be sub-optimal as far as the whole diversified corporation is concerned.

The SBUs concept of planning represents a break from traditional planning as based on the principles that: A diversified corporation should be managed as a 'portfolio' of businesses for purposes of achieving the overall corporate strategy. Each business unit, which should be reduceable to a unit serving a clearly defined product-market segment, should pursue a clearly defined strategy based on its distinctive competence in the market segment it is serving, and this strategy should contribute towards the achievement of the overall corporate strategy. 'The total portfolio of business should be managed by allocating capital and managerial resources to serve the firm as a whole - to achieve balanced growth in sales, earnings, and asset mix at an acceptable and controlled level of risk. In essence, the portfolio should be designed and managed to achieve the overall corporate strategy' (Hall, 1978).

In discussing the process and structure of SBU planning the Hofer and Schendel (1978) approach is going to be followed.

\section{Hierarchies of strategy}

In multi-divisional or multi-business corporation, strategic planning takes place at three levels, namely corporate, business, and functional levels. Hofer and Schendel (1978) identify four components of any organization strategy, around which the three levels of strategy can be characterized. These components are:

(i) Scope - the extent of the organization's present and planned interactions with its environment. This is the organization's mission or domain choice, which is finally represented by its product/market choice.

(ii) Resources Development - this has to do with the level and patterns of the organization's past and present resource and skill deployments and how these help the organizations to achieve its goals.

(iii) Competitive advantages - the organization's distinctive competence which comes about owing to its unique positions vis-a-vis its competitors. The organization or company achieve its competitive position as a result of its scope decisions and its pattern of resources development and deployment.

(iv) Synergy - this is the joint or assembly effects that are sought from the organization's resource deployment and/ or scope decisions.

\section{Corporate strategy}

At corporate level the scope component of an organization strategy is critically important. The type of business(es) the company would like to be in is the name of the game at this level. The next most important component has to do with resource deployment among products/businesses. Competitive advantage and synergy are important for related products or firms, but less so to the conglomerates. With conglomerates the synergy is usually thought of in terms of how the different firms, products, etc. reinforce each other in sharing corporate staff, financial resources, and top management skills.

Corporate managers usually present their strategic statements in the form of financial and non-financial terms, social and ethical obligations of the corporation, and in the specification of the current set of major plans that are to be pursued (Vancil, 1976). Among other things, corporate managers try to achieve balanced profit payoff and business risk, feasibility and consistency of and among different business/product plans, and the specification of tasks, responsibilities and timetables of strategic planning cycles corporate-wide (Bales, 1977).

In using a portfolio approach to strategic planning, certain common steps are followed. These are:

(i) The establishment or identification of strategic business units. This involves the process of aggregation and disaggregation of corporate activities. The essence of this process is to choose a level of aggregation 'that is meaningful strategically, i.e., a level at which plans are drawn up and implemented, and at which strategic decisions can be made relatively independently of strategic decisions for other units.' (Abell \& Hammond, 1979).

(ii) The determination of business factors which are important both in assessing the current performance of a product/business planning unit and the projection of its future performance under, say, no change in strategy, aggressive strategy, etc. The Boston Consulting Group (BCG) use relative market share, market growth rate, and cash revenue flow. The BCG approach uses a four-square grid product/business portfolio matrix. Each corporation's product/business is plotted in the matrix according to its percentage growth rate in sales and its relative market share position. The size of each circle in the matrix is proportional to the sales revenue generated by each product/business. General Electric has developed a more detailed nine-cell portfolio matrix based on long-term product-market attractiveness and business strength/competitive position. Product-market attractiveness is taken as a composite projection of market size, market growth rate, competitive structure, profitability, technological and social impacts, etc. On the other hand, business strength or competitive position is taken to be a function of market size and growth rate, market share, profitability, margins, technology position, skills, image, calibre of management, etc. (Hall, 1978). Hofer suggests a fifteencell matrix in which businesses are plotted in terms of their competitive position and their stage of product/ market evolution.

(iii) Each strategic planning unit is evaluated in terms of the 
Doterminant

Investment intensity

Market share

Market growth rate

Life cycle state

Marketing expense/sales

Effoct or impact

(a) As investment intensity rises ROI declines.

(b) Large investment and high marketing intensity equals poor ROI

(c) Capacity utilization is vital when fixed capital intensity is high.

(d) High capital intensity and small market share equals disaster.

(a) $\mathrm{ROI}$ is closely related to relative market share.

(b) Market share is most profitable in vertically integrated industries.

(c) High R \& D spending depresses ROI when market share is weak.

(d) Capacity utilization is most important for low-share business.

(c) Heavy marketing depresses ROI for lowshare business.

(f) Market share and quality are partial substitutes for each other.

(a) A rapid rate of new product introduction in fast-growing markets depresses ROI.

(b) $R \& D$ is most profitable in mature, slow growth markets.

A narrow product line, in early or middle stage of the life cycle, is less profitable than at late stage.

(a) High R \& D plus high marketing depresses ROI.

(b) High marketing expenditures depresses ROI especially when quality is low.

Figure 1 Determinants and impacts on ROI (Abell \& Hammond, 1979).

Determinant
Relative market share

Investment intensity
Effect or impact

(a) High relative share improves cash flow; high growth decreases it.

(b) High share and low investment intensity produce cash. Low share and high investment intensity result in cash drain.

(c) High relative share produces cash - especially when marketing intensity is low.

(a) Low or medium growth coupled with low investment intensity produces cash; High growth coupled with high investment intensicy is a cash drain.

(b) Harvesting share when investment intensity is low produces cash; building share when investment intensity is high is a cash drain.

(c) Investment plus marketing intensity results in cash drain.

(d) Few new product introductions coupled with low investment intensity produces cash.

Figure 2 Determinant of cash flow (Abell \& Hammond, 1979).

business factors indicated in (ii) above. Figures 1 and 2 show factors which have been found by Profit Impact of Marketing Strategy (PIMS) in U.S., to be important in influencing the level of return on investment (ROI) and cash flows respectively.

(iv) Each strategic planning unit is classified in accordance with its position when treated against the business factors indicated. In the BCG portfolio approach the following classification is used:

(a) 'Dog' or 'Cash trap'. This represent a strategic planning unit with low market share in a low growth market.

(b) 'Cash cow' or 'Bond'. Any SBU in this category has a large market share in low growth rate market. (c) 'Question marks' or 'problem children'. Any SBU in this category is in a high growth rate market but enjoys a low share of the market.

(d) 'Stars' or 'Savings accounts'. SBU in this category have high market share in high growth rate markets.

(v) The chosen business factors and the classification of SBUs into different categories bring about certain implied or suggested strategies that should be applied to each planning unit. The usually implied or recommendable strategic handling of portfolio SBU elements are as follows:

(a) 'Dogs' and 'cash cows' are managed for short-term cash flow. In the long run, 'dogs' are divested or eliminated, while 'cash cows' ultimately become 'dogs' as their competitive position declines. 'Cash cows' should make cash available to the 'problem children' and 'stars'.

(b) 'Question marks' must either get into the 'star' category or get out of the portfolio.

(c) 'Stars' are short run cash consumers and are managed for long-term position. In the long run, as their segment attractiveness or growth rate ultimately declines, they will become 'cash cows' to support the next round 'stars' (Hall, 1978).

\section{Business level strategies}

Strategy at this level is mostly focussed on how to compete in a particular industry or product/market segment. This means that distinctive competences and competitive advantages are usually most important at this level. Synergy is sought through the integration of different functional-area activities within an individual business. Policy/strategic decisions include product(s) line, market development, distribution, research and development, human resources, major manufacturing system design, finance utilization, etc. Resources have to be deployed among different functional areas. The strategic management process at this level involves: Current assessment of business status; generating and evaluating alternative strategies; and developing an action programme for chosen strategy (Bales, 1977).

\section{Profit economic analysis}

The physical generation of product costs and the determination of where economic leverage lies need to be thoroughly performed, given that this information is usually hidden by financial accounting systems. This information helps business managers to conduct sensitivity analysis to possible variations in volume, price, cost elements, manufacturing facilities and operations, distribution, and customer servicing requirements.

\section{Segmenting the market}

If the basic criteria of market segmentation are considered met, business managers will use different bases to segment their markets, such as end-use applications of products, user industries and customer characteristics, product performance characteristics, channels of distribution, etc.

All factors that are likely to affect different segments' growth, profitability, etc. are determined and the marketing mix elements are combined in the best ways possible - ways that will have relevant impacts on different market segments.

\section{Profiling competitors and supplies}

Competitors, product attributes, marketing levels, likely product costs and profitability, product development, and technological innovations are all assessed. Possible reactions of competitors to alternative feasible strategies adoptable by 
corporate businesses are also determined.

Suppliers' potential behaviours are also important to be taken into account. This will include the financial, technological, and manpower capabilities of suppliers. Added to this, the possible temptations (with associated costs) of suppliers to integrate forward are of critical importance to business managers. Having done all the necessary analysis business managers evaluate possible strategies in terms of profits payoff, investment cost, feasibility, risk, and long-term impact to overall corporate health. In doing so, business managers specify the risks and payoffs probabilities associated with each alternative strategy and this information is made available to top management at corporate level.

Having done all this it is important that business managers should also provide detailed implementation programmes for chosen strategies, indicating, among other things, recommendable changes in organization structure, budgeting, levels of manpower utilization and deployment, facilities investments, etc.

The scheme of analysis takes into account the competitive position of a strategic business unit (SBU), given the stage of market evolution. For instance, a SBU in a strong - average competitive position at the development stage of market evolution needs to pursue other things being equal, a shareincreasing strategy. On the other hand a SBU in a strongaverage competitive position at the maturity - saturation stage of market evolution need to pursue a profit strategy.

\section{Functional level strategy}

At the functional level the key emphasis is on the maximization of resource productivity. Synergy and the development of distinctive competence are important strategic components. The functional-area managers achieve synergy through the co-ordination and integration of activities within a single function. A functional-area manager's objectives might include cost effectiveness, productivity, quality and customer services, the rate of sales growth, management of company - distribution channels relationships, etc. It should be appreciated that the functional area is at the action level. The business-level strategies and ultimately the corporate plans are effectively implemented at the functional level.

\section{Organization structure for SBU portfolio management}

The business corporations, using portfolio planning approach, have chosen strategies of diversification (concentric of conglomerate), with semi-autonomous strategic units reporting to corporate headquarters and conforming to broad corporate objectives and policies for purposes of meeting corporate strategic business mission. Each strategic business unit is usually headed by a general manager and pursue its own business strategy. General managers of strategic business units usually report directly to corporate vice-presidents or group general managers who in turn report to the chief executive at corporate level. Typically there is a corporate strategic planning staff responsible for corporate strategic planning.

The concept of responsibility accounting requires that each manager should be held accountable for the activities over which he has control. This is an extension of one of the classical principles of organization: Authority should be equal to responsibility.

Strategic business units are usually organized as profit centers or investment centers. Professor Vancil distinguishes between the two as follows: Profit centers are areas where the manager is responsible for the best combination of costs and revenues. His objectives is to maximize the bottom line, which is the profit that results from his decisions and decisions executions. Investment centers are units where the manager, in addition to profit-center responsibilities, is responsible for the magnitude of assets employed. $\mathrm{He}$ is expected to make trade-offs between current profits and investments to increase future profits. The manager's objectives under investment centers is to maximize his return on investments (Vancil, 1973). The decentralization of a significant amount of decisionmaking authority under diversified multi-product or multibusiness corporations is rationalized on the grounds that general managers of individual strategic units are in a better position to choose the right market niches at their respective market areas, and are in a better position to respond quickly to competitive changes and other market dynamics. Diversification and decentralization reduce the need to gather and process information at the corporate top hierarchy, which easily experiences overload and consequently the bureaucratic delays in decision-making. Strategic business units organized either around markets, product, or geographical categories represent the creation of self-contained tasks. Information gathered and processed by self-contained units is less in both quantitative and variable terms, and, accordingly, more reliable than it would be the case if the corporation as a whole collected and processed information for all its units operating at different market environments. The corporate staff essentially resembles the creation of lateral relations that help to see to it that all the sub-units of the corporation are focussed to corporate strategic mission and also helps to handle information gathering and processing for purposes of coping with uncertainty across traditional line-authority relationships. Strategic units may also have their divisional-planning staff with staff relationship to divisional managers and functional (dotted-line) relationship to corporate staff (Galbraith, 1973).

\section{The general limitations of the assumptions of portfolio strategic management}

The top-down strategic management processes in diversified corporations are represented by the development of major corporate goals and matching master corporate strategies. On the other hand the bottom-up strategic management processes are represented by functional programmes and business/ division goals and strategies which are set within the parameters of major corporate goals and master strategies. The ultimate objectives of such processes are ideally to come out with an optimal business portfolio - well-balanced in terms of business units which should be principally balanced around the 'stars' and 'cash cows'. Such a portfolio ensures a diversified corporation with relatively high amounts of investable surplus cash owing to high market share in low cost structures (and hence high cash flow) from the 'cash cows'. This surplus cash is made available to high market share/ growth rate businesses as represented by 'stars'.

For the ideal optimal portfolio to be attainable with a high level of acceptance and satisfaction by a corporation's members, the immanent decision-making processes must be characterized by objectivity information adequacy, rationality and the subordination of individual managers' interests and goals to the interests and goals of the corporation as a whole.

Concerning the organization structure, the implicit assumption is that it matches the corporation's growth strategies. This is to say that structure follows the growth strategy of the corporation.

\section{Strategy formulation as a political process}

The above general assumptions of portfolio strategic 
management follow the classical normative-rational model of decision-making. Such a model does not represent decisionmaking in organizational set-ups.

It is a simplistic view to merely reckon that organization structure follows the growth strategy of the firm. The current structure of a firm at any given time is an embodiment of institutionalized previous strategy(ies). It also represents the roles of occupants, power, and influence distribution. At any given time the different members of the firm including external stakeholders are differentially satisfied with its goals, structure, processes, etc.

The operational effect of the above factors is that any significant change in strategy, if it has to take place at all, has to be sponsored by the dominant members, coalitions, etc. that are either not satisfied with the current state of affairs or who perceive that their interest would be further safeguarded by certain strategic changes. Those who stand to lose as a result of the change of the current strategy would use whatever powers, influence, etc., they have in the current organizational framework to block, manipulate, restructure the situation, and influence the perceptions of their opponents as to what best should be done in strategic terms for the company.

Under these realistic appreciations of the behaviour of members of organizations, the current structure will normally influence the adoption of a new strategy (Galbraith \& Nathanson, 1978).

Peter Lorange illustriously sums up the above contention when he observed that: 'Because the current structure and process of the firm reflects a specific power balance, strategy formulation and selection becomes essentially a political interaction among coalitions. In addition, the organisation design process and variables determine the design of the strategic planning process itself.'

The conflictual behaviour of organizational incumbents, as depicted in the above discussion represents political actions and processes. As MacMillan (1978) puts it 'a political action takes place when an actor (person, group, organisation etc.) recognising that the attainment of its goals is influenced by the behaviour of other actors in the situation, undertakes action against the others to ensure that its own goals are achieved.'

Unless an organizational role occupant has an overwhelming legitimate authority and power over all others (and this is rare), he or she would enter into coalitions with role occupants who share the same views around specified issues. As a result of membership to coalitions an individual incumbent within the organization acts as his own agent; agent of his/her coalition; and as an agent of the organization as a whole. The upshot of this exposition is that since strategymaking processes are essentially decision-making (choiceseeking processes), the behaviour of participants is determined or influenced by the perceived impact of such choices to the needs and interests of the 'principals' they represent.

It should be clear by now that the assumed normativerational strategic management actions and processes to attain optimal business portfolios may be untenable because of the behaviour of role occupants within organizational set ups. The above discussion has been general: It has been a critique to to the general limitations of the assumptions of portfolio strategic management. What follows below is the discussion of specific actions, processes, and systems associated with strategic management in diversified and SBU-structured corporations.

\section{The specific limitations of the assumptions of portfolio strategic management}

The limitations of SBU strategic planning are going to be discussed around the following areas: Information gathering and processing, the evaluation and rewarding of managers, organizational stigma vs individual manager's self-concepts, intra-organizational power relationships, management styles, and corporate culture.

\section{Information gathering and processing}

Under the rational-normative SBU concept of planning the multi-divisional corporation is assumed to have adequate information-gathering and processing capacity not only to evaluate each strategic unit's performance but also to evaluate market characteristics of each product/business unit.

This is to say that general managers of product/business units have, together with their planning staff, thorough knowledge of their respective markets. These managers impartially and objectively report about their products/ business markets performances. There are also implied harmonious working relationships between the corporate staff and general managers of strategic units and group vicepresidents or group managers whenever such structures exist. A number of studies and cases have shown that such assumptions are an exception rather than a rule. In most cases the corporate staff, which in some corporations operates at considerable geographical distance from individual strategic units, does not have all the necessary information about the market characteristics of each product/business unit. Furthermore, corporate staff and general managers of individual strategic units are usually locked in conflicts arising from a number of sources. For instance, corporate staff is evaluated on the performance of the whole corporation, while on the other hand, general managers are evaluated on the performance of their individual products/businesses. The corporate staff is not considered neutral by the strategic units' general managers, and since it engages in organization processes that affects the careers of the managers involved, the usefulness of corporate staff is always calibrated in personal terms by such managers (Uyterhoeven, Ackerman \& Rosenblum, 1977). It can be bluntly stated that information made available to corporate staff for purposes of evaluating performances of individual product/business as well as market dynamics is always loaded with biases. The process is further complicated by the practical problem of finding indisputable discriminant factors which unequivocally discriminate between a 'star', 'cash cow', 'dog', etc.

Furthermore, it can be stated that there are different types of 'stars', 'problem children', 'dogs', etc.

For purposes of achieving economies of scale and responsibility allocation, information-gathering and processing facilities tend to be centralized under the corporate staff acting as management information system (MIS) personnel. Since the sources of corporate information pool are the individual strategic planning units, corporate planning staff and other MIS staff, there is a high possibility of discrepancy between information held and used by SBUs, managers, and that held and used by the corporate planning staff.

The unpredictability of competitive and complex environments within which multi-divisional/SBU-structured corporations operate and the multiplicity of conflicting demands from coalitions within and without the corporation prevent clearcut solutions to available alternatives. 'In the absence of clearcut solution, the chosen alternative is the result of political processes. The greater the ambiguity, the greater the influence 
of politics in determining the outcome, and the greater the influence of the current distribution of power' (Galbraith \& Nathanson, 1978).

The doctoring of information by sponsors of certain strategic choices, acting in their fiduciary roles as representatives of different coalitions, makes an objective evaluation of proposed actions difficult. Information possessed by any coalition or representatives of coalitions is used as a strategic resource to effectuate preferred strategic options. In SBU/divisional-structured organization an objective evaluation of strategic proposals is further undermined 'by the loss of information as proposals filter upward through the organizational hierarchy' (Cohen \& Cyert, 1973). As information embodied in strategic or investment proposals filter upwards from functional to corporate levels of diversified corporations, the degrees of freedom for upper levels are reduced. During this 'selling process' a number of crucial details concerning proposals, available alternatives, etc, are lost.

Information-gathering and processing activities have other crucial roles and consequences for the optimality of any SBU portfolio. Information is required to determine SBU boundaries; evaluate current performance of SBUs; classify SBUs within the growth-share matrixes; determine the goals and strategies to be pursued by particular SBUs; determine the amount of resources to be made available to different SBUs; and specify the performance standards against which SBUs managers are to be evaluated.

The conclusion to be made here is that, with a special emphasis on SBU/Divisional structured corporations, the limited amount of information available to corporate top management to guide the overall behaviour of their business portfolio's is, more often than not, manipulated and doctored. Objectivity and rationality may be lost with the political whirlwind as coalition compete for organizational attention and resources.

\section{Evaluation and rewarding of managers}

The logical evaluation and reward system of managers of 'portfolio units' should be the one using multiple performance criteria, taking into account differentiated strategic goals followed by individual SBUs based on their individual classification. Each manager of a SBU should be evaluated and rewarded on the basis of the areas over which he/she has complete control. It is also important that there should be a clear causality relationship between individual SBUs management decisions and their results. The corporate staff and managers (group vice-president, group managers, executive presidents, financial controllers, etc.) should be evaluated and rewarded on the basis of corporate performance which essentially is an aggregate performanc of SBUs under the corporation

There are a number of problems associated with establishing performance criteria and the evaluation of managers at different levels of organization structure with, not only functionally differentiated responsibilities, but differentiated units as well. Coupled with the problem indicated above is the perception of each manager as to whether he/she has effective control of decision-making processes that ultimately affect his/her performance achievement and consequent reward. It is also important to note that a reward system is pervasive and should not be thought of only in terms of dollar salaries, bonuses, etc. Promotions (positions in the organization that enhances promotability), resource allocation, unit classification, organization status conferment, etc. need to be taken into account.

The few related issues indicated above help to highlight the mundane organizational experiences that managerial evaluation and rewarding processes are highly controversial and political within organizations. The larger a corporation is, the more complicated the intra-organizational political processes for resources allocation, performance criteria determination, performance evaluation and consequent rewarding.

The reported present managerial control and reward by diversified corporations following SBUs planning concept are reported to fall within the following continuum: At one extreme there are firms that have adopted SBUs planning concept but still reward and promote managers on traditional (single factor criterion); at the other end of the continuum are companies like General Electric (U.S.), which uses different standards for performance measurement. There are problems in either extreme, including whatever combinations within the continuum. The single criterion traditional performance-measurement and reward system ignores the fact that different managers are assigned to pursue different strategies, and that different products/businesses operate at different markets; different products/businesses are in industries (including technology dimensions) that differ in resource combination for certain level of performance, etc. The multi-factor approach brings about the problem of complexity: Managers of products/businesses that meet the preferred biases of top management based on the strategic corporate mission are likely to have preferential treatment. For instance, any top management which is evaluated on earnings per share is more likely to be earnings-biased and the managers of products/businesses that are strategic in contributing to corporate earnings are likely to be rewarded more favourably; more resources will be allocated to them and the mobility clusters for promotion purposes are likely to be traceable through the preferred product/businesses. Knowing what matters to top management, SBU managers would tailor their strategic requests to the interest of top management and not necessarily to the interest of their units and the optimality requirement of the corporation's business portfolio (Carter, 1971). In addition to the above complications, there is a lot of subjectivity involved in any process having to do with the determination of performance standard and performance measurement. The multi-factor approach is more likely to enhance such subjectivity than to reduce it. Lastly, it can be stated that the managerial behavioural outcome owing to 'reinforcement dosses' consequent to the multi-factor approach is likely to make it difficult to transfer managers from one SBU to another. The rigidity in managerial resources utilization within a conglomerate corporation leads to sub-optimal utilization of such scarce resources and is more likely to lead to a suboptimal business portfolio.

\section{Organizational stigma vs individual managers' self- concepts}

The rational-normative assumption or implication of the products/business portfolio strategic planning and management is that all SBUs are equally valued by the corporation and, therefore, their classification to 'stars', 'dogs', etc. is only for planning and positioning purposes. It has already been argued that top corporate management have their biases which are based on their personalities, management styles, functional and educational background, evaluation system exercised upon them, etc. If this is true, an organizational stigma of being 
a manager of a 'star'. A 'dog' stigma may be incompatible with the self-concept of group vice presidents and SBUs general managers. There is also bound to be job security anxiety in the SBUs that have been called upon to be harvested or divested. Furthermore, in strongly unionized corporations such strategies are likely to be resisted or to bring about a lot of labour relations problems.

Under these conditions SBU managers and union leaders will engage in political activities to either maintain present SBUs classifications or to change them depending on the outcomes of doing so.

\section{Intra-organizational power relationships}

An organization is a social system typified by interrelated behaviours of individuals who perform tasks that have been differentiated into several distinct sub-systems. The concept of organizational power is an important one in the interrelationships of individuals and sub-units forming the total organizational system. Power is a social behavioural concept which is only relevant where different individuals, sub-units, social systems, etc. have some relationships such that the behavioural outcome or the determinant of such behaviour is influenced by such interrelationships. A social unit has power on the other social unit if it significantly determines its (other unit) behaviour (Hickson, Hinings, Lee, Schneck \& Pennings, 1971). In business corporations, individuals, departments, divisions, strategic business units, etc. wield different organizational power 'units'. Hickson, et al. (1971) identifies three important intra-organizational power dimensions:

one unit affects the probability of another behaving in a particular manner.

(ii) Domain. The number of units whose probabilities of behaving in particular manners are affected by one unit.

(iii) Scope. This has to do with the range of a unit behaviour that is influenced by another unit(s).

Different units get their power based in organizations like business corporations from:

(i) Centrality. The degree to which the activities of a unit are interlinked into the organization system. This has to do with the impact of a unit's activities to the output of the organization as a whole.

(ii) Substitutability. This has to do with whether or not the organization can obtain alternative performance for activities performed by a particular sub-unit.

(iii) Coping with uncertainty. If one sub-unit is responsible for coping with environmental uncertainty for the benefit of others, its power base will increase.

The above power bases represent strategic power resources which, when applicable to a particular organizational situation, are deployed by their wielders to induce or to coerce, or to resist inducements or coercion from other units (MacMillan, 1978).

The discussion about intra-organizational power is made worthwhile because the concept of SBU portfolio analysis and management tends to assume away the existence of power conflicts within diversified corporations. It is assumed that business units classification is objectively arrived at and that strategies followed are optimal to the corporation as a whole. Typically it could be asked as to who is likely to be more powerful between general managers (vice presidents) of 'cash cows' and 'dogs', 'dogs', and 'stars'. If one strategic unit is a supplier of intermediate goods to other units, its power (owing to its centrality) in relation to recipient strategic units is more likely to be enhanced. It was also stated in this article that, in the event of top management being evaluated and rewarded on earnings per share, strategic units contributing more towards the overall corporate earnings will wield more power because they are considered more critical by top management. The argument submitted on this issue is that, because of intra-organizational power relationship, it is more likely than not to have sub-optimal resource allocations within the product/business portfolio which would generate suboptimal corporate portfolio earnings. If this happens the very purpose of product/business portfolio analysis and management will be defeated or undermined.

\section{Management styles and corporate culture}

The diversification of corporation, especially when achieved through mergers and acquisitions, also entails the entrance to the corporate (base business) culture and style of management by managers with different management styles and who are imbued with different 'cultures'. Typically, some top managers of acquired businesses are retained to run the acquired businesses as strategic units within the corporate business portfolio. This is more so if the corporation followed a conglomerate diversification strategy. The required or implied management style which results from the classification of the acquired business within the corporate business portfolio have, in a number of reported cases, been found to be in conflict with the management style of managers who managed the business as a separate entity before acquisition. Any attempts to socialize these managers to the corporate style of management and role prescription (arising from strategic unit classification in the corporate portfolio) have been resisted in a number of reported cases.

Differences in management styles and interests of managers of acquired and acquiring businesses have also been a source of conflict between corporate staff of the acquiring firm and managers of acquired strategic business units. It can be inferred, therefore, that given the problems of socializing retained managers of acquired businesses to the corporate (acquiring corporation) style of management and culture, the benefits of product/business portfolio analysis and management might either be delayed or never attained.

\section{The interventionist demand of external constituences}

The thrust of this article is to deal with the behaviour of internal constituences as it affects the rationality of strategy making in diversified corporations. This approach should not be construed to mean that the demands from external constituencies are relatively unimportant. In some cases external demands actually dictate feasible strategies to corporations. This is the case even in the celebrated private-enterprise economies. The mere size and hence visibility of diversified conglomerates leads to a situation whereby the different units of the organization interface with differentiated sub-environments whose stakes are affected positively or negatively by the corporation's goals, strategies, policies, and operations.

MacMillan (1978) categorize interest groups outside the organization into symbionts and commensals. The former represents those elements of the environment on which the organization is dependent for its inputs; and, the symbionts in turn depend upon the organization to take their outputs. The latter category represents those elements in the environment that are trying to attract the organization's symbionts.

While this categorization serves a very good purpose as a shorthand, there is a need to amplify the concept of inputs and outputs as described in the organization/symbionts relationships. Inputs incorporate more than just raw materials, 
human resources, investments funds, etc. Acceptance, toleration, and support of an organization's goals, strategies, and operations by symbionts are important inputs that corporations require. This is even more important with big visible corporations as exemplified by conglomerates. Similarly, the outputs (which the organization has to take into account in its strategy-making processes) of the symbionts include their goals, policies, strategies, and operations. They also include symbionts' perceived acceptable norms of behaviour for societal institutions.

The irrefutable and conflicting demands of powerful symbionts may constitute primary constraints on a corporation. Goals set and strategies formulated by the affected corporation are more of a compromise or represent sequential attention to conflicting demands. They are by no means optimal. The corporation will tend to generalize its policy commitments so that different symbionts 'can see some scope for achieving their specific purposes' (MacMillan, 1978).

In describing an adaptive mode of strategy making Henry Mintzberg (1973) captures the problem of diversified corporations trying to meet multiple and conflicting demands of symbionts and internal coalitions. Mintzberg's description is that: 'The adaptive organisation is caught in a complex web of political forces. Unions, managers, owners, lobby groups, government agencies, and so on, each with their own needs, seek to influence decisions. There is no one central source of power, no one simple goal. The goals of the organisation is characterised by bargaining among these groups, with each winning some issues and losing others. Hence, the organisation attends to a whole array of goals sequentially, ignoring the inconsistencies among them. The organisation cannot make decisions to "maximise" any one goal such as profit or growth; rather it must seek solutions to its problems that are good enough, that satisfy the constraints'.

From his studies, James Quinn (1980), provides reasons why executives may prefer not to announce specific goals as assumed in normative strategy-making processes. The top executives interviewed maintained that the communication of specific goals leads to:

(i) Undesired centralization, since it has the effect of telling subordinates that certain issues are closed and 'that their thoughts about alternatives are irrelevant'.

(ii) Focus for opposition, for it may provide an otherwise fragmented opposition with focal points to rally around.

(iii) Rigidity, because the executive ego accompanying publicly announced goals make it difficult to change them.

(iv) Security, consideration concerning relation of the company with its competitors.

Quinn (1980) also found that effective managers in large organizations consciously and simultaneously try to integrate information - analysis, power-political, and organizational psychological 'processes into their actions at various crucial states of strategy development'.

The conclusion to be drawn from the discussion so far is fairly obvious. When the internal constituences or coalitions are combined with external symbionts and the actions of commensals, the rational-normative approach in SBU portfolio strategic management represents an ideal or an approximation of what actually happens.

\section{Implications to top management}

The main objective of this paper was to show how structures, processes and systems as organizational attributes affect strategy formulation and implementation in diversified corporations. These attributes, taken together with demands from external coalitions, lead to political behaviour of role occupants. At this point few implications of such behaviour to top managers will be mentioned, essentially in passing.

It is important that top managers have to be fully cognizant of the fact that organizational goals, strategies, and policies are differentially preferred or ranked by different members of the coalition(s) or constituences. These perceptions lead to political processes. Such political processes are 'spontaneous, natural, and necessary phenomenon in the organisation' (MacMillan, 1978). They represent the dynamics needed by corporations to enhance their internal capabilities as they respond to external environmental demands. Political actions and processes do not represent anarchy but the dynamisms that are crucial for the survival of any corporation.

In their roles as strategy architects, organization builders and leaders, top managers should be experts or at least sufficiently alert about the political context within which individual subordinate managers play their fiduciary roles as representatives of different hierarchies of coalitions.

Top managers should be adept in structuring or restructuring the situation as well as incumbents' perceptions as to which issues should receive what priorities. This is to say that, since coalitions develop around certain issues, the role of top management is to structure or restructure the conditions within which issues are developed and to influence the perception of role occupants as to which issues deserve priority considerations. Having done so, the next move is to channel political processes in the direction that suits the organization's interest.

To manage a balance among constraining and inconsistent demands top managers should utilize the tools of compromise generalization of goals, and policy commitments to sequentially attend to more complex and less concrete issues. In dealing with external symbionts and commensals it is important to determine beforehand possible counter-strategies from such quarters.

To predict such possible counter-strategies, top management should possess information about values and structures of dominant coalitions within the symbionts and commensals organizations. It is important to determine the current and potential policy commitments of the symbionts and commensals; the alternatives available to them; and the resources at their disposals.

With such information top management can determine within the law, ideology and ethics of the country, what options are available. These options would range from accommodation (joint commitment, co-optation, and coalescence) to manipulation (coercion, inducement, obligation, and persuasion) (MacMillan, 1978).

\section{Conclusion}

In this article an attempt has been made to show that the logic and the expected optimal SBU portfolios are hard to achieve principally because of organizational attributes (structure, power differentiation, conflicting interests, rewards, and information systems, etc.) which influence political behaviour of role incumbents. Goals, strategies, and policies finally arrived at are either generalized or are no more than compromises. Owing to conflicting demands from internal and external coalitions and the limited amount of information, managers can only satisfice rather than maximize. The attainment of optimal business portfolios is either hardly attainable or is a fleeting process - once attained it cannot be maintained as yesterday's losers try to develop new political strategies aimed at reversing past losses. 
This outcome is not by itself illogical or stupid. It is the essence of organizational behaviour. Top management should be adept in managing such behavioural processes.

\section{References}

Abell, D.F. \& Hammond, J.S. 1979. Strategic Market Planning. New Jersey: Prentice-Hall.

Bales, C.F. August 1977. Strategic Control: The Presidents Paradox. Business Horizon.

Carter, E. 1971. The Behavioural Theory of the Firm and TopLevel Corporate Decision, Adm. Sci. Q., 16.

Cohen, K. \& Cyert, R. July 1973. Strategy: Formulation, Implementation and Monitoring. J. Bus., vol.46.

Galbraith, J. 1973. Designing Complex Organisations. California: Addison-Wesley Publ. Co. Inc.

Galbraith, J. \& Nathanson, D. 1978. Strategy Implementation: The Role of Structure and Process. New York: West Publishing Co.

Hall, W.K. Feb., 1978. SBUs: Hot, New Topic in the Management of Diversification. Bus. Horiz.

Hofer, C.W. \& Schendel, D. 1978. Strategy Formulation:
Analytical Concepts, St. Paul, Minnesota: West Publishing Company, 25.

Hickson, D.J., Hinings, C., Lee, C., Schneck, R. \& Pennings, J. June 1971. A Strategic Contingencies Theory of IntraOrganisations Power. Adm. Sci. Q., vol.16, (2).

Lorange, P. Implementation of Strategic Planning. Englewood Cliffs: Prentice-Hall Inc.

MacMillan, I.C. 1978. Strategy Formulation: Political Concepts. St. Paul: West Publishing Co.

Mintzberg, H. 1973. Strategy-making in Three Modes. Calif. Manage. Rev., vol.XVI, (2).

Quinn, J.B. 1980. Strategies for Changes: Logical Incrementalisms. Homewood: Richard Dr. Irwin, Inc.

Thompson, A.A. \& Strickland, A.J. 1980. Strategy Formulation and Implementation. Dallas: Business Publications, Inc.

Uyterhoeven, H., Ackerman, R. \& Rosenblum, J. 1977. Strategy and Organisation. Homewood: R.D. Irwin, Inc.

Vancil, R.F. March-April 1973. What kind of Management Control do you need? HBR.

Vancil, R.F. Winter 1976. Strategic Formulation in Complex Organisations. Sloan Manage. Rev. 